\title{
O FUTEBOL COMO ELEMENTO DE IDENTIFICAÇÃO SOCIAL E PATRIMÔNIO CULTURAL DO BRASIL: DOS PRIMÓRDIOS A CONTEMPORANEIDADE DO ESPORTE BRETÃO
}

${ }^{1}$ Vinícius Triches

\section{RESUMO}

Introdução: Considerado o esporte mais popular do planeta, o futebol tem sido um objeto de estudo cada vez mais representativo do ambiente acadêmico no Brasil e em outros países. Objetivo: Apontar, com base em uma retomada histórica, o processo de consolidação do futebol como elemento da identificação social na história e contemporaneidade cultural da sociedade brasileira. Método: Realizou-se uma pesquisa qualitativa, de caráter exploratório, segundo o alcance de desenho, e pesquisa bibliográfica, quanto aos procedimentos técnicos. Resultados e Discussão: Percebeu-se que as formas primitivas de futebol tinham elementos que associavam as suas práticas a aspectos culturais, educacionais ou de celebração de vitórias, ao mesmo tempo em que o esporte, logo após a sua criação oficial, foi rapidamente espraiado para outros países, processo que, junto com outros fatores, contribuiu decisivamente para a emergência desse como um fenômeno global de massas. Conclusão: $O$ Brasil é um desses expressivos celeiros esportivos e culturais. Enquanto transmissor inconteste de uma manifestação cultural relevante, o futebol acabou historicamente se transformando em elemento de mobilização das pessoas com base no entendimento do próprio Brasil. Paixão que normalmente passa de pai para filho, o gosto pelo futebol e a sua imensa popularidade deu-se também com base na fidelidade dos torcedores aos seus "clubes do coração", que, uma vez escolhidos, acabam por representar uma identidade social permanente.

Palavras-chave: Sociedade, Futebol, História, Cultura, Brasil.

\section{SOCCER AS AN ELEMENT OF SOCIAL IDENTIFICATION AN CULTURAL HERITAGE IN BRAZIL: FROM THE PRIMORRIALS TO THE CONTEMPORANEITY OF SPORT BRETÃO}

\section{ABSTRACT}

Introduction: Considered the most popular sport on the planet, soccer has been an object of study increasingly representative of the academic environment in Brazil and other countries. Objective: To point out, based on a historical recovery, the process of consolidation of football as an element of social identification in the history and cultural contemporaneity of Brazilian society. Method: A qualitative, exploratory research was carried out, according to the scope of design, and bibliographic research, regarding technical procedures. Results and Discussion: It was noticed that the primitive forms of football had elements that associated their practices with cultural, educational or celebration of victories aspects, at the same time that the sport, soon after its official creation, was quickly spread to other countries, a process that, together with other factors, contributed decisively to the emergence of this as a global mass phenomenon. Conclusion: The Brazil is one of those expressive sporting and cultural granaries. As an undisputed transmitter of a relevant cultural manifestation, football has historically turned into an element of mobilization of people based on the understanding of Brazil itself. Passion that normally passes from father to son, the taste for football and its immense popularity was also based on the fans' loyalty to their "heart clubs", which, once chosen, end up representing a permanent social identity.

Keywords: Society, Football, History, Culture, Brazil.

1 Universidad Argentina John. F. Kennedy (UK). Endereço: Calle Piedras, 655. Buenos Aires, Argentina. E-mail: vtriches@yahoo.com.br 


\section{INTRODUÇ̃̃O}

Relevante campo de observação da realidade social e humana, o esporte é cada vez mais um objeto de interesse do ambiente acadêmico, com base no estudo e pesquisa referenciada em trabalhos relacionados às mais diferentes áreas do conhecimento humano. Neste universo, o futebol é campo árduo para a efetivação de pesquisas que envolvam as áreas humanas, saúde e sociais, dentre outras.

Considerado o esporte mais popular do planeta, o futebol teve como marco oficial de sua criação a segunda metade do século XIX na Inglaterra. Entretanto, várias formas de futebol já haviam sido vistas antes em diferentes locais, todas estas consideradas contornos rudimentares do desporto que logo se difundiria para outros países nos momentos posteriores.

É nesse sentido que o objetivo do presente foi apontar, com base em uma retomada histórica, o processo de consolidação do futebol como elemento da identificação social na história e contemporaneidade cultural da sociedade brasileira. Assim, destacou-se a evolução histórica do esporte no mundo, apresentado desde o momento em que se distinguem as suas formas pré-históricas até o momento de sua origem e sistematização das regras, com o partilhamento de uma paixão global e de massas nas décadas seguintes, constituindo um fenômeno que, em solo nacional, consolidará a noção do "país do futebol".

$O$ presente artigo foi dividido em quatro partes, sendo a introdução a primeira. A segunda apresentou os principais procedimentos metodológicos adotados. Já a terceira parte teve como destaque os resultados e discussão do estudo, iniciando nos primórdios rudimentares do futebol, tendo como foco o período anterior da sua criação oficial, apresentando a seguir a origem e a sistematização das regras motrizes do desenvolvimento do esporte que já nas décadas posteriores acabou por se tornar uma paixão global e de massas, vindo a seguir um breve histórico dos eventos que consolidaram - futebol no Brasil, destacando seus momentos iniciais até a materialização da paixão brasileira pelo esporte e, finalmente, refletiu-se sobre $o$ pertencimento $e$ a autoestima do povo brasileiro com base nesse esporte, tendo como cenário a sociedade e a cultura do futebol no Brasil. Por fim, a quarta e última parte apresentou a Conclusão/Considerações Finais.

\section{MÉTODO}

$\mathrm{Na}$ busca do objetivo do presente trabalho, realizou-se uma pesquisa qualitativa, de caráter exploratório, segundo o seu alcance de desenho, e pesquisa bibliográfica, quanto aos procedimentos técnicos adotados. Gil (2014) destaca que uma pesquisa bibliográfica é aquela que é desenvolvida a partir de material já elaborado, sendo estes principalmente os artigos científicos e os livros. Já a pesquisa exploratória é aquela que, de acordo com Biagi (2012), normalmente é escolhida quando se trata de estudos preliminares, sobre assuntos pouco sistematizados, cuja conveniência seria "[...] usar esse desenho quando se está buscando indícios de um problema [...]" (BIAGI, 2012, p. $54)$.

Foram consultadas bibliografias da literatura recente sobre o processo histórico de consolidação do futebol enquanto um fenômeno social de caráter mundial, reforçado como elemento de identificação social, buscando assim perceber os principais elementos que o constituíram desde os seus primórdios, tendo como base a Sociologia do Esporte.

Adotou-se, assim, a leitura e análise de artigos científicos, trabalhos de conclusão de curso e livros sobre as temáticas do futebol no Brasil e no mundo, de acordo com elementos históricos, buscando o confronto entre as diferentes perspectivas adotadas, de acordo com os autores selecionados. 


\section{RESULTADOS E DISCUSSÃO}

O futebol nos diferentes recantos do mundo: os primórdios rudimentares do desporto

O futebol, da forma que é conhecido nos dias atuais, teve a sua origem na Inglaterra no ano de 1863 , de acordo com a maioria dos autores, como, por exemplo, Murad (2012), Dienstmann e Denardin (1999) e Melo (2000). Considerado o maior fenômeno de massas do mundo, o esporte foi exportado para os diferentes cantos do planeta ao longo dos últimos 157 (cento e cinquenta e sete) anos.

Entretanto, deve se ter em conta que existiram diferentes "formas de futebol" anteriores ao Código de Regras de origem inglesa, em que se percebe que "[...] não era futebol exatamente, mas jogos muito antigos, considerados ancestrais deste esporte, porque se chutavam bolas - no caso qualquer objeto redondo, esférico" (MURAD, 2012, p. 64). A própria palavra futebol tem origem na significação inglesa football, que pode ser traduzido com bola no pé ou pé na bola.

Dienstmann e Denardin (1999) afirmam que é do período pré-histórico o registro de desenhos feitos em cavernas há cerca de 7 (sete) mil anos de homens chutando objetos, inclusive crânios humanos. Em período posterior, enquanto os egípcios faziam adoração ao Sol e os povos babilônicos à Lua, outros povos acreditavam que o chute de objetos esféricos era uma excelente maneira de espantar os maus espíritos.

Melo (2000) afirma que muitos são os que afirmam que as origens do futebol acabaram por se perder no tempo. Supostamente, as origens que podem ser destacadas estão, para o autor, entre os maias, os egípcios, os chineses e a antiga Roma.

Uma das primeiras "modalidades de futebol", de acordo com Murad (2012), teria sido o Tsu (tsu = chutar e tsu/chu = bola). Praticado na China ao redor de 2600 a. c., a atividade era na verdade um ritual de guerra, não tendo relação com jogo ou competição esportiva, sendo uma prática que acontecia quando, após os combates, a tribo vencedora jogava um "futebol" em que as "bolas" eram as sete cabeças dos inimigos derrotados. Para tanto, escolhiam a do chefe e a dos seis melhores guerreiros que haviam vergado em campo de batalha.

Outra modalidade anterior ao futebol propriamente dito dos dias de hoje foi a do Kemary $(k e=$ jogo e mary = pés), de origem japonesa e datada praticamente na mesma época que o Tsu. Com um significado completamente oposto ao primeiro, a prática é considerada um cerimonial de forte teor pedagógico e de reconhecida qualidade estética, sendo ainda praticada nos dias atuais. De acordo com Murad (2012):

[...] Trata-se de uma celebração para o autoconhecimento, o autocontrole e a meditação, preparatórios à disciplina e à concentração na escola, no processo de aprendizagem e na conquista do saber. É praticado sob o maior silêncio possível - o mesmo silêncio que a milenar educação defende para a sala de aula. De extrema delicadeza, a plasticidade do Kemary é elegante, artística, e a indumentária é refinada e nobre. A marcação de ritmo e movimentos é feita por melodias típicas do folclore japonês, que, ao fundo, discreta e suavemente, ambientam a coreografia. (MURAD, 2012, p. 66).

Já o Thachtli foi praticado ao redor de 1500 a. c. nas Américas do Norte e Central com o simbolismo de uma guerra entre o dia e a noite, a luz e a escuridão, adotando a prática de decapitação de jogadores da equipe derrotada, como também acontecia no Tsu. Tal processo acontecia porque havia uma crença de que o sangue, uma vez jorrando, acabaria por divinizar a terra e, desse modo, "[...] o sagrado tentaria controlar o excesso de emoções" (MURAD, 2012, p. 68).

Ainda nas Américas, mais especificamente na América do Sul, remonta uma tradição dos povos indígenas no período de 1000 a. c., o Matanaaríti. Jogado com uma bola de mangabeira (borracha) que era revestida de caucho, um tipo de madeira leve, a prática permitia o uso das pernas, costas e nádegas para o controle da bola, embora a disputa quase sempre se desse através de cabeçadas.

O Matanaaríti tinha, enquanto sua finalidade, um sentido educacional, principalmente para as crianças e jovens, visto que destacava como uma de suas regras principais o respeito pelo jogo e pelos demais participantes durante a prática. Tornou-se, assim, uma das formas rudimentares da expressão que hoje é conhecida como o fair play, ou seja, uma atuação esportiva que destaca a necessidade de respeitar as regras, o adversário e o público como pressuposto fundamental do esporte.

Em um período mais recente destacam-se a prática do Epyskiros e do Harpastum. O primeiro, de origem grega e 
praticado ao redor do século IV a.C., e o segundo, oriundo de Roma no período de I a.C., foram praticados no contexto de florescimento máximo das culturas destas civilizações.

Ambos eram jogados com elegância e disciplina quase que exclusivamente pelas camadas mais elevadas da sociedade, ou seja, a nobreza, sendo estes os cidadãos da polis (cidade-estado) grega, ou os aristocratas, conhecidos como patrícios, no Império Romano. Já quando praticados por gente do povo, a atividade tornava-se mais livre e solta, o que deixava a mesma mais bonita e espontânea, mas ao mesmo tempo mais vigorosa e, em certos momentos, violenta, de acordo com Murad (2012).

O antecessor imediato do futebol foi o Calcio ou Gioco del Calcio e sua primeira aparição foi no século XIV na Itália. Teve como seu primeiro campo de prática desportiva a superfície congelada do Rio Arno, em Florença, onde foi fácil fazer com que a bola deslizasse, embora manter o equilíbrio fosse quase impossível. Tal aspecto é importante quando se pensa as características do jogo de futebol atual, dado que:

Essa condição particular fazia o jogo, a princípio, exigir do praticante mais equilíbrio, mais habilidade corporal e, por isso, sua prática se tornava mais elegante e coreografada. Por outro lado, também exigia muito preparo físico dos jogadores, que se empenhavam na ginástica. Portanto - interessante! mesclava técnica e força, habilidade e preparação física. (MURAD, 2012, p. 71).

Com a popularização da atividade esportiva, no momento em que essa passou a ser jogada nas ruas, tornou-se mais competitiva e menos controlada por regras e normas, momento em que o número de jogadores e de torcedores tiveram grande crescimento, fazendo com que as partidas começassem a ser aguerridas tanto dentro e como fora de campo.

Considerando estas formas rudimentares de práticas de atividades antecessoras do futebol que são caracterizadas por uma ambiguidade entre a arte e a violência, o que se verifica é que estas características sempre acabaram por permear o esporte em sua fase antiga e a atual.

\section{O futebol nos diferentes recantos do mundo: origem e sistematização das regras motrizes do desenvolvimento de uma paixão global e de massas}

Murad (2012) vai destacar que o futebol foi criado em 26 de outubro de 1863 na Inglaterra, momento este em que as regras do jogo serão unificadas em Londres, no período da segunda fase da Revolução Industrial.

A unificação das regras faz com que o jogo acabasse por se tornar um esporte, visto que passa a ter um regramento universal, isto é, igual para todos, dentro de um contexto em que a ordem e a disciplina passam a serem ferramentas que tem como meta a civilidade nas relações sociais. Assim, o futebol nasce como consequência e contribuição do processo civilizacional. Entretanto, faz-se a seguinte pergunta: porque o futebol acabou por nascer na Inglaterra?
Melo (2000) menciona que os primórdios da maioria dos esportes estão situados neste país, visto que foi lá que "[...] as antigas práticas da população (erroneamente chamadas de pré-esportivas) começaram a se organizar enquanto um campo relativamente autônomo" (MELO, 2000, p. 14), ao contarem com fatores como uma lógica interna específica, calendários próprios e corpo de técnicos especializados, o que fez com que fosse gerado um mercado de consumo com sentido completamente diferente ao praticado anteriormente. A Taça da Inglaterra teria sido, de acordo com Carvalho e Marchi (2006), a competição mais antiga de futebol do mundo.

Oriundo das escolas burguesas inglesas, a unificação das regras que consagraram o futebol moderno e a sua posterior disseminação nestes ambientes escolares foi realizado fundamentalmente com o intuito de controlar os impulsos da juventude, visando preparar os futuros líderes do império britânico, ao apregoar valores como o cavalheirismo, boa conduta e honestidade, dentre outros, segundo destacado por Melo (2000).

Dentro da mesma perspectiva de análise, Rossi e Mendes Jr. (2014) mencionam também que as escolas inglesas neste período funcionavam não apenas como centros de ensino, mas também de diferentes práticas esportivas, sendo estas praticadas nas horas livres em seus pátios. Apesar da predominância do críquete, os recém-criados rugby e o futebol começavam a despertar cada vez maior interesse. 
Rossi e Mendes Jr. (2014) estacam ainda que em 1863 foi na Universidade de Cambridge, através da publicação das suas próprias regras para a prática, em um total de 14 (catorze), que o nascimento formal do futebol ocorreu. Foi nesse período que o advogado e fã de esportes Ebenezer Cobb Morley começou a reunir os clubes onde a modalidade era praticada bem foi criada a Associação Inglesa, juntando todos aqueles que se dispusessem a jogar de acordo com as regras estipuladas por Cambridge.

Nos anos posteriores aos do nascimento formal do futebol são agregados novas regras e inovações, visando um melhor funcionamento e atenção a novas demandas surgidas oriundas da maior prática do mesmo. Estas novidades para a época ainda estão vigentes nos dias atuais, tendo sido adaptadas ao longo das décadas. São elas, de acordo com o ano de seu aparecimento, segundo destacado por Dienstmann e Denardin (1999), dentre outras, por ordem cronológica:

- 1866: aparece a regra do impedimento, visando criar maior participação de todos os jogadores em todas as faixas do campo;

- 1868: o árbitro e o bandeirinha aparecem oficialmente como figuras mediadoras do jogo;

- 1869: é criado o tiro de meta:

- 1871: o goleiro passa a ter o direito de usar as mãos em toda a sua faixa de campo defensivo e a bola passa a ter peso mínimo e máximo para começar as partidas;

- 1872: surge o escanteio e a falta com tiro livre, esta última ainda sem distância mínima em relação a presença do jogador adversário;

- 1873: define-se que a troca de campos dos times começará a ser feita no intervalo dos jogos e não mais após cada gol;

- 1877: é dado o direito ao árbitro de advertir os jogadores;

- 1880: estabelece-se que os jogos deverão ter duração de uma hora, possuindo dois intervalos com trinta minutos cada;

- 1891: os pênaltis são introduzidos e as goleiras passam a ter redes;

- 1892: é introduzido o tempo extra (acréscimos) nas partidas;

- 1912: as ações dos goleiros ficam limitadas somente a sua própria área, bem como estes passam a vestir roupas diferentes dos companheiros de seu time;

- 1958: as substituições de jogadores começam a ser permitidas, mas somente por lesão. Somente a partir de 1970 é que os treinadores começam a poder fazer duas substituições por partida, independente do motivo.

Carvalho e Marchi (2006) destacam que o futebol é então exportado, após consolidar-se na Inglaterra, para outros países: França (1872), Suíça (1879), Bélgica (1880), Alemanha, Dinamarca e Holanda (1889), Itália (1893) e aos países da Europa Central em 1900.

Dada à proporção que o esporte começou a tomar neste período, é criada em 21 de maio de 1904 a Football International Federation Association (FIFA), cujo objetivo era a imposição jurídica de uma entidade para a representação do futebol em caráter mundial. Seu primeiro presidente foi o francês Robert Guérin, entre 1904 e 1906, e o segundo foi o inglês Daniel Burley Woolfall (1906 a1918).

O primeiro grande êxito da nova entidade é a sua admissão como membro da International Board no ano de 1924, já sob a presidência do francês Jules Rimet, que ajudaria a criar anos depois a Copa do Mundo de seleções, que teve sua primeira edição no ano de 1930, com a vitória do Uruguai, sendo este também o país sede do evento. A primeira edição do evento teve a participação de 13 (treze) seleções nacionais, sendo 7 (sete) da América do Sul, 2 (duas) da América do Norte e 4 (quatro) da Europa.

Atualmente 0 esporte pode ser considerado um fenômeno mundial, praticado em quase todos os países do mundo. Melo (2000) destaca que existem mais países filiados a FIFA do que as Organizações das Nações Unidas (ONU) e o principal evento do esporte, a Copa do Mundo de seleções, mobiliza mais público no local e através de transmissões esportivas do que os Jogos Olímpicos, acontecimento que reúne mais de vinte modalidades esportivas. Com 193 (cento e noventa e três) nações ligadas a FIFA, 0 futebol congrega oficialmente milhões de jogadores registrados profissionalmente, isso sem contar com os outros milhões que são praticantes ocasionais, ainda de acordo com o autor.

A Copa do Mundo de seleções evento teve, até a última edição, como grandes campeões, respectivamente, o Brasil (com 
cinco títulos conquistados nos anos de 1958, 1962, 1970, 1994 e 2002); a Alemanha (1954, 1974, 1990 e 2014) e a Itália (1934, 1938, 1982 e 2006), com quatro títulos cada; os bicampeões Uruguai (1930 e 1950), Argentina (1978 e 1986) e França (1998 e 2018); e, com um único título, Inglaterra (1966) e Espanha (2010).

$\mathrm{Na}$ América do Sul, o futebol é o esporte mais popular em praticamente todos os seus países, com destaque para nações como o Brasil (será apresentado a seguir), Argentina, Uruguai, Peru, Chile, Colômbia, Bolívia e Paraguai, possuindo seleções nacionais que foram vencedoras nas edições Copa América, maior competição disputada entre os países desse subcontinente. Os maiores campeões são, respectivamente, o Uruguai, com 15 (quinze) títulos, e a Argentina, com 14 (catorze).

O ponto de partida do futebol no América do Sul tem, de acordo com Marmol (2008), o Rio da Prata como expoente. A origem estaria na data de 20 de junho de 1867, momento da fundação, por parte do capitão inglês Thomas Hogg, do Buenos Aires Football Club, com a primeira partida oficial sendo disputada no Buenos Aires Cricket Club. De acordo com Frydenberg (2011), os sócios do clube convocaram os jogadores para a realização da partida, mas as repercussões e consequências do evento acabaram por serem efêmeras.

Futebol em território tupiniquim: da chegada ao esplendor do "país do futebol"

A mais tradicional explicação para a chegada do futebol ao Brasil, bem como a de sua socialização como prática esportiva no período posterior, é aquela que relaciona tais fatos a figura de Charles Miller, filho do engenheiro ferroviário escocês John Miller e de Carlota Alexandrina Cox. Essa explicação é quase uma unanimidade entre 0 grande público e entre os pesquisadores, de acordo com Melo (2000), que destaca que Miller foi o introdutor do futebol no Brasil porque no ano de 1894, ao trazer duas bolas de futebol ao regressar da Inglaterra, organizou os primeiros jogos entre os sócios do São Paulo Athletic club.

Porém, uma rápida pesquisa histórica mostrou que alguns antecedentes foram também importantes para a posterior difusão do esporte, antecipando-se a versão oficial que destaca Miller como o introdutor oficial do desporto no país. Deve ser mencionado que, assim como no restante no mundo, o país antes mesmo de seu descobrimento havia experimentado formas rudimentares de futebol, com a prática, por parte dos povos indígenas, de jogos similares, segundo destacado por Nogueira (1995).

O papel desempenhado por Miller é fundamental porque este, de acordo com Melo (2000), teve uma atuação preponderante na organização e difusão do futebol entendido como um campo esportivo, isto é, composto por competições, clubes e entidades que fazem a sua direção.

O que deve ser considerado é o fato de que, no período anterior a chegada de Charles Miller, conforme já comentado, o esporte já era praticado em terras brasileiras em diferentes locais, conforme variados relatos, com a adoção das normas que haviam sido elaboradas na Inglaterra. Mas como o futebol havia adentrado ao Brasil? O esporte havia chegado basicamente por dois canais fundamentais: através das escolas ou por meio de funcionários ingleses que moravam no país e trabalhavam em empresas de seu país de origem.

Melo (2000) afirma que os colégios jesuítas foram os responsáveis pela prática do esporte no país porque a Igreja Católica passou a adotar uma nova postura no final do século XIX na Europa em relação a esse, basicamente ao dar importância a alguns critérios básicos. Inicialmente, o esporte tornou-se pasteurizado, isto é, transformou-se em uma verdadeira instituição, adotando regras claras e direção clara. Além disso, o aspecto educacional do futebol foi dado como importante, visto sua utilização em território inglês para o controle e propagação de valores burgueses, característica esta que foi usada com a mesma finalidade pela Igreja. Também é desse período a mudança de atitude de alguns setores religiosos em relação a prática de atividades corporais, consideradas em épocas anteriores como detentoras essenciais do pecado, mas que a partir deste momento começaram a ser encaradas como formas saudáveis de "gastar a energia", bem como se notou a crescente popularidade do esporte, fator que pressionava a Igreja a aceitar a sua prática.

Dentre os principais colégios jesuítas que começaram a adotar o futebol como prática pedagógica, se destacam o Colégio São Luiz, em Itu (SP), e o Colégio Anchieta, em Nova Friburgo (RJ). No primeiro, o futebol começou a ser praticado ainda em 1880, sendo que quando as bolas vindas da Europa acabavam furando, eram substituídas por bexigas de boi; já no segundo, os exercícios físicos, entre eles o futebol, foram introduzidos logo após a fundação da escola, ocorrida no ano de 1886.Também o futebol esteve 
presente no mesmo período em escolas não religiosas, ao observar o regimento do Ginásio Nacional (antigo Colégio Pedro II) do ano de 1892, que mencionava a permissão de diversos "jogos escolares", citando dentre estes o futebol, segundo destaca Melo (2000).

A segunda via de entrada do futebol no país foi por meio de funcionários ingleses que estavam morando no Brasil para trabalhar em empresas de seu país de origem. Neste sentido, destacam-se organizações do ramo ferroviário, entre elas a São Paulo Railway e a Leopoldina Railway, bem como companhias de navegação e bancos, dentre outras. Carvalho e Marchi (2006) destacam que os funcionários das empresas ferroviárias citadas aprenderam a praticar o esporte, bem como jogado entre si nos períodos de folga do trabalho, ainda no ano de 1882, portanto, 12 (doze) anos antes de Charles Miller retornar ao Brasil.

Para Rossi e Mendes Jr. (2014), uma terceira via da entrada do futebol no país, esta não considerada por Carvalho e Marchi (2006), foi a prática do esporte por marinheiros no litoral brasileiro. Os autores afirmam que os ingleses, franceses e holandeses, sempre a bordo de navios mercantes ou de guerra, aproveitavam uma escala ou a chegada a um destino definitivo para "bater uma bolinha" desde meados do século XIX. Tal fato teria acontecido pela primeira vez em 1874, no pedaço de areia em frente aonde hoje fica 0 Hotel Glória, no Rio de Janeiro, de acordo com Rossi e Mendes Jr. (2014). Quatro anos mais tarde, foi a vez da tripulação do navio britânico Crimeia organizar uma "pelada" em frente ao palácio da princesa Isabel, no bairro de Laranjeiras, zona sul da capital federal, com o consentimento de sua alteza.

Como foi visto anteriormente, o paulista do bairro do Brás Charles Miller desempenhou ação fundamental na difusão do futebol no Brasil. Filho de um inglês que havia vindo trabalhar na São Paulo Railway, Miller havia ido a Inglaterra para estudar, ao mesmo tempo em que acabou se envolvendo intensamente com a prática do futebol em sua escola, a Banister Court School, em Southampton, inclusive até defendendo clubes locais, de acordo com Melo (2000). Ao retornar ao Brasil, trouxe consigo um conjunto completo para a exercício daquela que se tornaria uma paixão nacional: duas bolas, um papel com as regras do jogo, chuteiras e as camisas de equipe, bem como as bombas para encher as bolas.

Dada a sua experiência e vontade de continuar praticando o esporte, esse se torna membro do São Paulo Athletic Club, mas logo percebe que o futebol não é praticado no clube. Em 1895 acabou por convencer então os demais sócios a praticarem mais efetivamente o futebol, momento em que são realizadas as primeiras partidas do esporte no Brasil.

Rossi e Mendes Jr. (2014) destacam assim que a Inglaterra deu ao Brasil não somente o primeiro jogador, mas também o primeiro dirigente esportivo. Apesar da preferência pelo críquete como atividade de lazer, Miller iniciará um processo da catequização:

Aos sábados, reunia os amigos e colegas de trabalho para ensinar o beabá do esporte: chutes, cobrança de lateral, passes, dribles, marcação. Os melhores da peneira de Charles Miller eram chamados para o time da São Paulo Railway - os pernas de pau continuavam na escolinha, até aprender ou reconhecer sua ruindade e desistir. O time da São Paulo Railway entrou em campo em 14 de abril de 1895, entre as ruas do Gasômetro e Santa Rosa, para enfrentar o The Gas Works Team, da companhia de gás, no primeiro jogo de futebol registrado no Brasil. [...] Foi uma estreia formal, mas não exatamente a primeira partida de futebol no Brasil. (ROSSI e MENDES Jr., 2014, p. 21-22).

Dienstmann e Denardin (1999) destacam que esse primeiro jogo, realizado num capinzal da Várzea do Carmo, teve jogadores que usaram calças compridas e que tiveram como primeiro ato para a realização da partida terem de enxotar o gado que estava pastando no local. Embora não tenha sido referenciado o tempo de duração da partida em manuscritos impressos da época, o time da ferrovia (São Paulo Railway) foi o vitorioso, com placar de quatro a dois.

Murad (2012) irá destacar que em seus primeiros momentos o futebol era considerado um esporte da elite, somente praticado para a busca do lazer por parte das camadas sociais mais elevadas. Com caráter amador, era "[...] disputado pelos filhos das famílias ricas, todos brancos, cultos, elegantes 
e com duplo sobrenome" (MURAD, 2012, p. 75). Entretanto, dada a sua forma de divertirse de maneira barata, simples para entendê-la e fácil de jogar, logo começa a chamar a atenção de uma parcela da população de origem e situação social excluída, pobre, mestiça e analfabeta. A dicotomia das práticas do futebol no Brasil em seus primeiros passos é descrita pelo autor com extrema clareza:

Nos clubes dos ricos perpetuava-se o esporte tal como chegou aqui: elitista, racista, excludente. Nas ruas, nas praças pobres, na várzea, na periferia das cidades, no entanto, era um movimento espontâneo dos desfavorecidos, que corriam atrás da bola como forma de afirmação social, uma vez que constatavam a possibilidade de serem bons em algo privativo das elites. (MURAD, 2012, p. 76).

\begin{abstract}
O processo de popularização e democratização do esporte que será considerado em tempos posteriores a maior manifestação da cultural brasileira se dará inicialmente, então, nas ruas (entre as décadas de 1910 e 1920), depois será através dos clubes (a partir da década de 1920) e logo a seguir abrangerá aos mais variados espaços com o seu crescimento e profissionalização, essa última oficializada no ano de 1933.
\end{abstract}

O primeiro clube de futebol brasileiro foi fundado no dia 19 de julho de 1900 na cidade gaúcha de Rio Grande, tendo recebido o nome de Sport Club Rio Grande, de acordo com Beloni (2020). Fundado pelo alemão Johannes Minnemann, o clube tinha 21 (vinte e um) atletas, todos de origem europeia. Seu primeiro título foi conquistado somente no ano de 1922, com a Taça do Centenário da Independência, competição instituída pelo governo do Estado do Rio Grande do Sul. Posteriormente, a data de 19 de julho acabou por ser oficializada como o dia do futebol brasileiro. Já o segundo clube a ser fundado no país foi a Associação Atlética Ponte Preta, criada 21 (vinte e um) dias depois do clube gaúcho (11 de agosto de 1900), na cidade de Campinas, no Estado de São Paulo. Os dois clubes ainda se encontram em atividades profissionais, com a Ponte Preta sendo um clube de constante participação na primeira divisão do futebol nacional, embora sem ter alcançados títulos expressivos ao longo de sua história. Já o Rio Grande tem participações mais regulares na segunda e terceira divisões do futebol gaúcho.

Nos dez anos seguintes inúmeros clubes foram criados focados exclusivamente no futebol, alguns desses com grande tradição no futebol brasileiro até os dias atuais. São eles:

- Fluminense Football Club: foi fundado em 1902, sendo o primeiro clube brasileiro a ostentar a palavra "futebol" no nome, tendo sido 31 (trinta e uma) vezes campeão carioca e 4 (quatro) vezes campeão brasileiro;

- Grêmio Foot-Ball Porto Alegrense: fundado em 1903, foi o primeiro clube de Porto Alegre a entrar em campo, tendo alcançado diversos campeonatos regionais, nacionais e internacionais;

- Bangu Atlético Clube: datado de abril de 1904, é o mais antigo clube oriundo de fábrica ainda em atividade profissional, tendo sido vice-campeão brasileiro e bicampeão carioca;

- Sport Club do Recife: criado em 1905, é o primeiro clube do estado de Pernambuco ainda em atividade a entrar em campo;

- Sport Club Penedense: primeiro clube alagoano ainda em atividade a ser fundado (ano de 1909).

Cabe o destaque que também foi dessa época a fundação de diversos clubes representativos até os dias atuais, mas que vieram a adotar a prática futebolística somente nas décadas posteriores, o que acabou gerando dúvidas relativas ao seu pioneirismo no esporte. Exemplos desses são o Clube de Regatas do Flamengo (criado em 1895) e o Clube de Regatas Vasco da Gama (1898), ambos do Estado do Rio de Janeiro, cujo foco na época de sua fundação esportiva foi a prática do remo como atividade principal.

Retomando a questão dos períodos passados pelo futebol brasileiro no que se refere as diferentes transformações e avanços, a fase ocorrida entre os anos de 1894 e 1932 também ficou conhecida como a era do amadorismo, mesmo que este fosse considerado, em certos momentos, um "amadorismo de gaveta" ou "amadorismo marrom", dado que já nas primeiras décadas do século $X X$ existiram jogadores que recebiam para jogar, mesmo que isso não fosse explicitamente revelado, dado que a 
ideia de pagar dinheiro para alguém jogar não era bem aceita socialmente, de acordo com Carvalho e Marchi (2006).

Foi dessa mesma época também que, de acordo com os mesmos autores, em função do processo de popularização do esporte, a pressão das torcidas dos clubes fez com que as agremiações comecem a repensar a questão da inclusão de jogadores não pertencentes a elite. Assim, no ano de 1923, a pressão atingiu o seu auge, momento em que o Vasco da Gama decidiu, sendo a primeira vez na história do futebol brasileiro, pela inclusão de negros e brancos analfabetos em seu time, decisão esta que será coroada com a conquista do campeonato carioca daquele ano. Essa se torna uma versão tradicional do processo de inclusão no futebol brasileiro, embora outras formas de participação de negros e/ou pobres, também sejam observadas em outras regiões em períodos anteriores, segundo Carvalho e Marchi (2006).

Também foi outro momento histórico a criação da Confederação Brasileira de Desportos (CBD), por sugestão do chanceler Lauro Müller, no ano de 1916, visando a organização do futebol no país, através de uma entidade máxima, bem como a sua representação no exterior.

Florenzano (2012) destaca que a fase que se iniciou a partir de 23 de janeiro de 1933, com a implantação oficial da profissionalização do futebol no Brasil, caracterizou-se pela consolidação de um período extremamente rico da história social deste esporte. O primeiro jogo da era profissional no país foi entre São Paulo Futebol Clube e Santos Futebol Clube, realizado no dia 12 de março deste ano, com vitória dos primeiros por 5 (cinco) a 1 (um), sendo o primeiro gol anotado por Artur Friedenreich, conhecido como "El Tigre". A partida foi realizada no Estádio da Vila Belmiro, na cidade de Santos, sendo que tal estádio ainda existe nos dias atuais.

A fase final do "amadorismo marrom" e os primeiros anos do profissionalismo significaram também o período de surgimento dos dois atletas que tiveram papel fundamental para a consolidação dos mitos do imaginário popular no futebol brasileiro: 0 próprio Friendereich e Leônidas da Silva. Os atletas, ao atingirem renome nacional, acabaram por fomentar a discussão sobre a imagem dos jogadores de futebol, bem como a relação latente e permanente entre negros e brancos no futebol, de acordo com Florenzano (2012).

Friedenreich foi o autor do único gol da vitória do Brasil contra o Uruguai, na decisão do Campeonato Sul-Americano de 1919. Mas seu principal gol se dava sempre a cada dia 13 de maio, data da abolição da escravatura no país, quando eram realizados os jogos comemorativos entre "Pretos X Brancos". Como era de origem mestiça (filho de um imigrante alemão e de uma afrodescendente), jogava um tempo em cada um dos times, "[...] desvelando a complexidade das relações raciais e a margem de manobra dos atores, bem como o jogo sempre aberto e indefinido das identidades coletivas (FLORENZANO, 2012, p. 2).

Já Leônidas da Silva, destacado e temido atacante de equipes como Botafogo de Futebol e Regatas, Flamengo e São Paulo, também teve papel fundamental no período de transição de um futebol com cor e classe social rígida e definida para aquele que seria o esporte favorito de praticamente todos os brasileiros independente de sua origem, classe social ou cor da pele.

$O$ atleta, que recebeu o crédito como $o$ inventor da célebre jogada da "bicicleta" no futebol, bem como foi agraciado pelo apelido "Diamante Negro" devido a sua grande habilidade com a bola nos pés, tem ainda uma conotação bem simbólica na discussão das questões raciais e sociais desse período, tão romântico para o futebol brasileiro.

Posteriormente, a consolidação do futebol como a "mania nacional" dos brasileiros se deu de forma definitiva nos anos 1970, momento da conquista do tri campeonato de seleções pelo escrete brasileiro durante a Copa do Mundo realizada no México. É nesse período que, de acordo com Carvalho e Marchi (2006), o futebol foi expandido para todo o território brasileiro, o que acabou por aumentar os interesses políticos, econômicos e sociais pelo esporte.

Uma das consequências desse processo foi a realização do primeiro Campeonato Brasileiro de Futebol, no ano de 1971, com a participação de clubes das regiões Sul, Sudeste e Nordeste na competição, o que assegurava uma dimensão mais nacional ao esporte. Para se ter uma ideia, o Torneio Roberto Gomes Pedrosa, seu antecessor, foi disputado entre 1951 e 1966 somente entre clubes do estado do Rio de Janeiro e São Paulo, abrindo vagas para os representantes de Minas Gerais, Rio Grande do Sul, Paraná e Bahia somente a partir de 1967, de acordo com Carvalho e Marchi (2006).

É também desse período a instituição da Lei $n^{\circ} 6.354 / 76$, que determinou os direitos para os jogadores profissionais, passando estes a terem férias, bem como determinou o 
período de intervalo entre as partidas realizadas. Tal lei dará origem a Deliberação $n^{\circ}$ 09/76, conhecida como a "Lei do Passe", responsável pela regulamentação das transações de vendas dos jogadores, segundo Rodrigues (2007).

O Brasil tornou-se uma potência do futebol mundial, com a conquista de inúmeros títulos tanto pela Seleção nacional como por seus clubes. Já a Copa do Mundo acabou sendo realizada no país em duas oportunidades: em 1950, com o Uruguai levantando a taça, e em 2014, com o título sendo conquistado pela Alemanha.

A Seleção Brasileira tornou-se campeã mundial nas Copas do Mundo de 1958, 1962, 1970, 1994 e 2002, sendo vice nos anos de 1950 e 1998. Quanto à Copa América, o Brasil teve até o momento 9 (nove) títulos conquistados, alcançados nos anos de 1919, 1922, 1949, 1989, 1997, 1999, 2004, 2007 e 2019.

Já os clubes brasileiros de futebol são extremamente competitivos nas competições internacionais, além de serem admirados mundialmente, tanto pelos títulos conquistados como pelos jogadores e equipes que marcaram a história do esporte.

Estes foram responsáveis por 10 (dez) títulos mundiais de clubes (três com o São Paulo, dois com o Santos e Sport Club Corinthians Paulista e um cada com o Sport Club Internacional, Grêmio e Flamengo), bem como 20 (vinte) conquistas da Taça Libertadores da América, sendo os principais campeões o São Paulo, Grêmio e o Santos (três), Internacional, Flamengo, Sociedade Esportiva Palmeiras e Cruzeiro Esporte Clube (duas) e, com um título cada, Corinthians, Vasco da Gama e Clube Atlético Mineiro.

Percebe-se que o futebol é um desporto espraiado para todas as 5 (cinco) regiões brasileiras, do norte ao sul do país. Tal elemento é percebido pela participação dos clubes de variados estados nas maiores e menores séries do campeonato nacional.
As maiores torcidas do país são, de acordo com Globo Esporte (2019), apresentando dados de pesquisa realizada pelo Datafolha, o Flamengo $(20 \%$ do total de torcedores), Corinthians (14\%), São Paulo $(8 \%)$, Palmeiras (6\%), Vasco da Gama (4\%), Cruzeiro (4\%), Grêmio (4\%), Internacional $(3 \%)$, Santos $(3 \%)$, Atlético Mineiro $(2 \%)$, Botafogo (1\%), Esporte Clube Bahia $(1 \%)$, Fluminense (1\%), Sport (1\%), Santa Cruz Futebol Clube (1\%), Fortaleza Esporte Clube (1\%), Esporte Clube Vitória (1\%) e Ceará Sporting Club (1\%).

\section{Pertencimento e autoestima do povo brasileiro com base no esporte: a sociedade e a cultura do futebol no Brasil}

Esporte de caráter integrador dos mais diferentes grupos sociais, o futebol foi, ao longo da história, uma das formas de visualizar o pertencimento, no que se refere a um determinado vínculo emocional ou afetivo a um clube ou seleção nacional ou regional. E também a integração, com base no agrupamento de determinadas classes ou categorias populares, mediante a sua prática esportiva, bem como a uma determinada causa em que o mesmo esteja envolvido.

Um dos fatores que fez com que o futebol no Brasil fosse, desde os seus primórdios, um esporte que atraiu grandes multidões para a sua prática foi o fato deste ser demasiadamente barato e de simples entendimento, o que tornava fácil para ser jogado, tanto pelas classes mais abastadas, como pela expressiva parcela da população brasileira que era excluída, pobre, mestiça e analfabeta, de acordo com Murad (2012).

Sobre esse processo de inclusão das classes menos favorecidas e a consolidação de uma forma de jogar e entender futebol no Brasil a partir dessa perspectiva, o autor destaca que:

A história social do futebol brasileiro é um capítulo de nossas lutas sociais, políticas e culturais. A popularização/democratização do futebol, fruto da resistência e das lutas das camadas desfavorecidas da sociedade, foi consolidada nas décadas de 1940 e 1950. Os setores pobres da população, antes impedidos de participar, foram se impondo e trazendo para o jogo um "jeito brasileiro", uma espécie de "estilo", uma "marca própria", por assim dizer. É uma herança de nossas identidades culturais indígenas, portuguesas e, sobretudo, negras. No "estilo" brasileiro de jogar, as raízes culturais de nossas classes oprimidas se fizeram presentes (MURAD, 2012, p. 77).

Essa formação histórica fez com que, ao longo dos tempos, para o autor, o esporte tenha se tornado uma paixão verdadeiramente 


\section{Futebol e Cultura}

coletiva que acaba por mexer com praticamente todo o país, independente dos diferentes grupos, classes sociais, padrão de renda, escolaridade e região. Assim, acabou por se tornar um símbolo muito forte dos valores culturais nacionais, constituindo um modo de ser do brasileiro, o que o leva a ser entendido como uma identidade coletiva nacional.

Considerado tradicionalmente 0 esporte mais popular do Brasil, Melo (2000) destaca que em solo brasileiro o futebol é uma prática cultural tão significativa quanto o teatro, o cinema e as artes plásticas, dentre outras. Entretanto, nenhuma das manifestações citadas tem um poder de mobilizar tantas pessoas ao mesmo tempo como o futebol, visto que mexe amplamente com as paixões, desejos e sentimentos dos torcedores envolvidos.

Segundo Murad (2012), talvez uma das explicações para o futebol ser tão importante na vida dos brasileiros é o fato de ter sempre representado as diferentes contradições sociais e os dilemas do povo. Permitindo, assim, ser uma forma de entender a sociedade através de diferentes campos: a formação étnica, a miscigenação, a musicalidade e a cultura corporal, dentre outros.

Também aspectos da estrutura social perversa do Brasil podem ser vistos através do esporte, sendo eles a concentração de renda, do poder e de oportunidades. É dessa forma que, através da experiência do futebol, "[...] podemos 'ler' a sociedade brasileira no que ela tem de positivo e de negativo" (MURAD, 2012, p. 80).

O futebol seria, então, para o autor, uma grande forma de representar a sociedade do Brasil, constituindo um conjunto de retratos da vida nacional, em que esses aspectos são seguidamente revelados nos campos, nas torcidas, nas comemorações e nas organizações dos torneios.

Todos esses locais e esferas mostram e nos lembram de diferentes paradoxos, ambiguidades e tensões culturais do Brasil. Ao mesmo tempo em que se percebe a alegria, a criatividade, a capacidade de organização independente, a possibilidade de luta, resistência, superação e democracia, o futebol também representa um componente nacional que está ancorado no autoritarismo dos dirigentes (políticos ou esportivos), o descaso das autoridades, a corrupção, a impunidade, a concentração de renda, a falta de oportunidades e a violência.

Carvalho e Marchi (2006) destacam que, na mesma linha que Murad (2012), o futebol no Brasil acabou por se tornar uma tendência instintiva, um resultado do povo e da sociedade. Para tanto, apresentam exemplos, como o fato de que uma ginga dentro de campo é equivalente ao "jeitinho brasileiro" de resolver/driblar os problemas do dia-a-dia e a onda de violência social, bem como a impunidade e o favorecimento de poucos, problemas típicos do cotidiano do brasileiro, é transferida repetidamente para o ambiente do futebol.

Dentro dessa perspectiva, o futebol é, para os autores, altamente influenciado pela sociedade, visto que é um veículo de permanência de valores sociais, ao mesmo tempo em que exerce influência na própria vida da sociedade brasileira, ao emanar seus valores, contradições e interesses no espectro variado de configurações sociais e culturais existentes.

Fácil também é perceber no Brasil os amplos e diferentes espaços que o esporte de origem inglesa ocupa na mídia tradicional (televisão, jornal e revistas, por exemplo) bem como nas consideradas modernas e alternativas (sítios eletrônicos, blogs e redes sociais) ao longo de uma rápida pesquisa.

Notícias que apresentam os principais resultados dos jogos do campeonato estadual, nacional ou continental, esses realizados na noite anterior, bem como as principais perspectivas para a próxima partida das equipes locais, regionais ou nacionais, no que se refere a formação tática e técnica e os reforços que serão agregados aos times no próximo jogo ou competição, recebem grande atenção e exposição por parte dos diferentes tipos de mídias comentados acima.

Esse processo de acompanhamento do futebol por parte da mídia teve início nas primeiras décadas do século $X X$, quando o esporte passa a ser um evento social que não é mais de interesse somente dos seus praticantes, mas também de uma massa expectadora e interessada pelo mesmo de forma permanente. Fatos como a vinda de equipes internacionais para o país, bem como as primeiras disputas interestaduais, entre 0 Rio de Janeiro e São Paulo, são eventos que colocam o esporte em evidência, de acordo com Melo (2000).

Também é desse período a participação do país nas primeiras competições internacionais do esporte. Inicialmente coroadas com fracassos, os êxitos logo são alcançados, com a glória máxima sendo alcançada em 1958, ano da conquista do primeiro título mundial de seleções pelo Brasil em campeonato realizado na Suécia. As Copas do Mundo passam a ser 
acompanhadas pelos brasileiros com uma paixão nacionalista, muitas vezes cooptada pelo contexto político do momento, visto que "[...] não era mais um simples jogo desinteressado. Era o país que estava em jogo" (MELO, 2000, p. 23).

Sendo um objeto de interesse constante por boa parte do público nacional, bem como também um "filão" interessante a ser atendido pela mídia, o futebol e suas principais dimensões é uma prática no Brasil que passa de pai para filho, tanto no que se refere ao amor a um clube, como também no imaginário da representação de algum aspecto de nossa sociedade. Assim:

Quantas músicas retrataram o futebol; quantos filmes, peças de teatro e novelas tiveram o futebol como personagem principal ou como cenário para suas tramas; quantas horas diárias as imprensas televisivas e radiofônicas gastam com o futebol; quanto espaço diário de jornal é dedicado a este esporte, em detrimento de outros; quantas emissoras de rádio transmitem o mesmo jogo, nas tardes de domingo. (DAOLIO, 2000, p. 33).

É dentro desse contexto que se pode verificar também que uma das formas de perceber a permanente popularidade do futebol está na extrema fidelidade dos torcedores aos seus clubes. De uma forma geral, percebe-se que independente da fase negativa do clube e o sofrimento e angústia que esses momentos tendem a representar, o torcedor acaba sempre por acreditar em dias melhores vindouros para a sua agremiação esportiva.

Daolio (2000) destaca que a fidelidade a um clube de futebol no Brasil vem desde o dia do nascimento, quando o garoto (ou garota) recebe um nome, uma religião e um clube de futebol para o qual deve ou deveria torcer a vida toda, processo esse que passa normalmente pelo pai. Vê-se, então, que o brasileiro aprende "[...] a torcer por uma determinada equipe de futebol, diferentemente das equipes de voleibol ou basquetebol que, como representantes de empresas, mudam de nome a cada temporada" (DAOLIO, 2000, p. 34-35).

O futebol pode ser visto então como um campo fértil para a percepção da identidade social, dado que a rivalidade clubística é calcada basicamente na diferença, de acordo com Morato (2005). No ato da escolha de um clube, está a aceitação e o reconhecimento do seu patrimônio, além da negação a tudo aquilo que é diferente.

Um clube pode ser visto como uma "tribo" diferente que vai manter suas crenças e tradições também diferentes, sempre "olhando" para todas as outras com desprezo e superioridade, dado que acredita que o "[...] seu time, a sua tribo, é melhor do que as outras em todos os aspectos" (MORATO, 2005, p. 93).

Também é interessante notar que no mundo dos esportes e, mais especificamente, do futebol, há uma extrema curiosidade por parte dos torcedores com o perfil de jogadores que acabaram por se tornarem ídolos, dado que foram coroados com grandes êxitos e conquistas pelos clubes e seleções.

Helal (2001a) destaca que normalmente "suas trajetórias de vida rumo à fama e ao estrelato costumam ser narradas na mídia de forma mítica, conferindo uma maior dramaticidade às conquistas" (HELAL, 2001a, p. 135). A observação histórica no Brasil das diferentes narrativas que resgatam a trajetória da vida dos ídolos de futebol enfatiza, principalmente, de acordo com o autor, aspectos como a genialidade e o improviso como os componentes fundamentais para o sucesso no esporte.

Entretanto, cabe nesse momento a seguinte indagação: porque um fenômeno de massas não é plenamente sustentável ao longo do tempo sem a presença permanente de "heróis", "estrelas" ou ídolos?

A resposta parece estar, conforme Helal (2001b), no fato de que esses agentes são uma "porta" que leva as pessoas a se identificarem com o evento esportivo em si, dado que os mesmos representam a "nossa comunidade" que frequentemente gosta de saudar e idolatrar situações em que o esportista acaba por sobrepujar obstáculos que são considerados aparentemente de caráter intransponível.

É dessa maneira que a missão a ser cumprida pelo "herói" é a de conceder dádivas aos seus semelhantes, visto que:

O herói parte do mundo cotidiano e se aventura numa região de prodígios sobrenaturais; ali encontra fabulosas forças e obtém uma vitória decisiva; o herói retorna de sua misteriosa aventura com o poder de trazer benefícios aos seus semelhantes. (CAMPBELL, 1995, p. 36 apud HELAL, 2001b, p. 154).

A percepção é que o futebol permanece sendo, ainda de acordo com o autor, um terreno extremamente fértil para que essa característica do "ídolo-herói" possa se 
reproduzir no sentido da produção de mitos e ritos que são relevantes para a comunidade.

Como são dotados de talento e carisma, os ídolos denotam características que acabam por singularizá-los e diferenciá-los do restante da população, que os percebe como " [...] paradigmas dos anseios sociais e através das narrativas de suas trajetórias de vida, uma cultura se expressa e se revela" (HELAL; MURAD, 1995 apud HELAL, 2001b, p. 154).

Damo (2014) vai destacar que, retomando o papel da identidade vinculada ao futebol e seu entendimento como esporte de diferenciados vínculos sociais e culturais, essa relação se dá devido à necessidade de compreender o processo clássico, mas sempre renovado, de qualquer dinâmica de grupo.

O campo do futebol é, fundamentalmente, voltado ao espetáculo, uma fonte generosa de questões a serem investigadas, na mesma perspectiva de Murad (2012). Assim, ali se apresentariam "[...] extensos e multifacetados os arranjos em termos de identidades e alteridades" (DAMO, 2014, p. 26)

O futebol vai representar, por sua estrutura, uma disputa bem demarcada entre um eu (ou nós) e um outro (ou outros), o que vai acabar favorecendo a instauração de aspectos como a identidade e a diferenciação. Esse processo é perceptível porque, de acordo com o autor, toda a partida de futebol é "[...] um rito do tipo disjuntivo, no qual os contendores, partindo de uma situação de pretensa igualdade, lutam para promover uma cisão entre vencedores e vencidos" (DAMO, 2014, p. 26)

Dessa forma, destaca que dois grandes sistemas de representação estão solidamente constituídos no futebol enquanto espetáculo. O primeiro sistema é relacionado aos clubes, denominado de clubismo, e o segundo direcionado às seleções nacionais, visto como patriotismo ou nacionalismo, dada a ausência de termos mais apropriados. De acordo com essa perspectiva:

Nesse futebol, um time jamais entra em campo apenas pensando nos interesses, expectativas e fragilidades de seus integrantes. Ele é preparado para algo mais importante, digamos, que é representar as aspirações de uma comunidade de sentimento, que pode ser um clube ou uma nação/pátria. (DAMO, 2014,p.27).

Essa maneira de perceber o futebol e o trato de um jogo e seu amplo contexto é facilmente vista, conforme já discutido por Melo (2000), na visão de que a Seleção Brasileira é a seleção de todos os brasileiros, e o "torcer" é representado como sinônimo de brasilidade e amor ao país, o que muitas vezes leva ao questionamento de que o povo brasileiro se identifica mais com as questões nacionais associadas ao futebol do que com a política, por exemplo.

\section{CONCLUSÃO}

Embora tendo a sua criação oficial datada do ano de 1863 na Inglaterra, puderam ser observadas formas rudimentares do desporto em períodos anteriores, algumas delas até anteriores a Cristo. De maneira simples, as formas anteriores se referiam a eventos que celebravam a arte ou a violência, sendo as primeiras relacionadas a aspectos culturais ou educacionais, enquanto as segundas tinham relação com celebrações de vitórias em guerras.

Com base nas 14 (catorze) regras originais do futebol este se consolida então enquanto esporte, sendo que nos anos posteriores, com sua maior prática na Inglaterra e a difusão para outros países, novas inovações são adotadas no mesmo, algumas delas até constituir-se em regramentos adicionais. A criação da FIFA nos primeiros anos do século $X X$, enquanto entidade do futebol em termos globais, e a edição do primeiro campeonato mundial de seleções de países (Copas do Mundo) no ano de 1930, são elementos fundamentais para a consolidação do esporte como um fenômeno global de massas até os dias de hoje.

Relativamente ao Brasil, acabou por se tornar 0 seu esporte mais popular independente de classe social, com representação expressiva na cultura e cotidiano nacional, sempre permeada por hábitos e sentimentos que denotam 0 pertencimento futebolístico, tanto no que se refere aos clubes ou a seleção.

Independente das polêmicas momentâneas, porém intermináveis, dentro e fora do campo, das posições pessoais relativas ao verdadeiro papel exercido pelo esporte na esfera social, é imprescindível o 


\section{Futebol e Cultura}

reconhecimento de que 0 futebol se consolidou como um elemento importante para a compreensão das diferentes realidades sociais, haja vista os vários olhares possíveis a partir do universo futebolístico.

Foi dessa maneira que a visualização dos aspectos históricos que materializaram esse fenômeno fundamentalmente sociológico, com base nas primeiras experiências com 0 desporto nas escolas e ruas, a formação dos primeiros clubes, a profissionalização do esporte e os elementos socioculturais que permearam o imaginário popular futebolístico, acabaram por se tornarem luzes no processo do entendimento necessário dos dias atuais.

Enquanto transmissor inconteste de uma manifestação cultural relevante, o futebol acabou ao longo do tempo sendo elemento de mobilização das pessoas com base em um maior entendimento do próprio Brasil. Principalmente quando se observa a sua principais realidades, problemas e contradições, muitas dessas históricas e que recorrentemente são retomadas.
Também, é evidente perceber que tal manifestação somente pode ser espraiada territorialmente por causa do relevante espaço ocupado pelo esporte ao longo das décadas na mídia tradicional, mas também mais recentemente nas mídias alternativas. Uma vez que as últimas sempre foram canal relevante para o acompanhamento dos jogos e dos debates que os campeonatos acabavam por suscitar.

Paixão que normalmente passa de pai para filho, o gosto pelo futebol no Brasil e a sua imensa popularidade deu-se também com base na fidelidade dos torcedores aos seus "clubes do coração", que, uma vez escolhidos, acabam por representar uma identidade social permanente, em que a diferenciação entre os "nós" (nosso clube) e o "eles" (clube rival) será a característica principal da rivalidade eterna. Dentro desse pertencimento clubístico, também merecerá destaque o papel dos ídolos dos clubes, que sempre serão a referência das vitórias alcançadas e da valorização dos símbolos do clube escolhido.

\section{REFERÊNCIAS}

BELONI, P. Dia do Futebol no Brasil: conheça as origens do esporte masculino e feminino. Batanga. Disponível em:< http://www.batanga.com.br/1042/dia-do-futebol-no-brasil-conheca-as-origens-do-esportemasculino-e-feminino >. Acesso em: 03 abr. 2020.

BIAGI, M. C. Pesquisa Científica: roteiro prático para desenvolver projetos e teses. Curitiba: Juruá, 2012.

CARVALHO, A. I.; MARCHI, F. L. de. Futebol: história e bastidores de uma paixão nacional. Goiânia: Vieira, 2006.

DAMO, A. S. O espetáculo das identidades e alteridades: as lutas pelo reconhecimento no espectro do clubismo brasileiro. In: CAMPOS, F. de; ALFONSI, D. (org.). Futebol objeto das ciências humanas. São Paulo: Leya, 2014.

DAOLIO, J. As contradições do futebol brasileiro. In: CARRANO, P. C. R. (org.). Futebol: paixão e política. Rio de Janeiro: DP\&A, 2000.

DIENSTMANN, C.; DENARDIN, P. E. Um século de futebol no Brasil: do Sport Club Rio Grande ao Clube dos Treze. Porto Alegre: APLUB, 1999.

FLORENZANO, J. P. Futebol e Racismo: o mito da democracia racial em campo. Futebol \& Cultura. Sociedade. São Paulo: Goethe - Institut São Paulo. 2012. Disponível em: <www.goethe.de/ins/br/sap/priffus/ges/pt9657066.htm> Acesso em 14 maio 2020.

FRYDENBERG, J. Historia social del fútbol: del amateurismo a la profesionalización. Buenos Aires: Siglo Veintiuno Editores, 2011.

GIL, A. C. Métodos e técnicas de pesquisa social. 6. ed. São Paulo: Atlas, 2014. 
GLOBO ESPORTE. Futebol. Maiores torcidas do Brasil: veja evolução de pesquisas de 1993 a 2019. Disponível em: < https://globoesporte.globo.com/futebol/noticia/maiores-torcidas-dobrasil-veja-evolucao-de-pesquisas-de-1993-a-2019.ghtml >. Acesso em: 27 fev. 2021.

HELAL, R. 2001a. As idealizações de sucesso no imaginário brasileiro: um estudo de caso. In: HELAL, R.; SOARES, A. J.; LOVISOLO, H. A invenção do país do futebol: mídia, raça e idolatria. Rio de Janeiro: Mauad, 2001.

2001b. Mídia, construção da derrota e o mito do herói. In: HELAL, R.; SOARES, A. J.; LOVISOLO, H. A invenção do país do futebol: mídia, raça e idolatria. Rio de Janeiro: Mauad, 2001.

MARMOL, F. Buenos Aires antiguo / Old Buenos Aires: Fútbol 1900-1940. Buenos Aires: Ediciones del Viajero, 2008.

MELO, V. A. de. Futebol: que história é essa?! In: CARRANO, P. C. R. (org.). Futebol: paixão e política. Rio de Janeiro: DP\&A, 2000.

MORATO, M. P. A dinâmica da rivalidade entre pontepretanos e bugrinos. In: DAOLIO, J. (org.). Futebol, cultura e sociedade. Campinas, SP: Autores Associados, 2005.

MURAD, M. A violência no futebol. São Paulo: Saraiva, 2012. (Coleção para entender).

NOGUEIRA, C. J. G. Educação Física na sala de aula. Sprint: Rio de Janeiro, 1995.

RODRIGUES, F. X. F. O fim do passe e a modernização conservadora no futebol brasileiro (2001-2006). Tese (Doutorado em Sociologia). Instituto de Filosofia e Ciências Humanas, Universidade Federal do Rio Grande do Sul, Porto Alegre, 2007.

ROSSI, J.; MENDES JÚNIOR, L. Guia politicamente incorreto do futebol. São Paulo: LeYA, 2014. 